\title{
Modelling occurrence probability of the Endangered green peafowl Pavo muticus in mainland South-east Asia: applications for landscape conservation and management
}

\author{
Niti Sukumal, Simon D. Dowell and Tommaso Savini
}

\begin{abstract}
The green peafowl Pavo muticus is a highly threatened galliform species that was historically distributed widely across South-east Asia. Evidence shows a recent population decline and range contraction for this species, linked with habitat degradation and over-exploitation. This study aimed to determine the current known distribution across mainland South-east Asia and investigate potential habitat that could host remaining viable populations and contribute to the long-term survival of the species. We used locations from historical and recent records and habitat variables from a geographical information system database to model the probability of occurrence and classify key localities according to their relative importance for the species. Our results showed that the green peafowl probably occurs in less than $16 \%$ of its historical range across mainland South-east Asia and that remaining locations are fragmented. Four confirmed and two potential stronghold populations were identified for the species, based on the localities with high capacity to contribute to its long-term survival in large contiguous patches. These were in central Myanmar, western and northern Thailand, eastern Cambodia/south-central Viet Nam and northern Cambodia/southern Lao. Threats vary amongst countries, with continued habitat loss and degradation in many areas and hunting particularly acute in Viet Nam, Cambodia and Lao. Most of the remaining populations are in protected areas but the protection level varies widely. We propose conservation actions for each stronghold population, in accordance with the nature of the threats and protection level in each area, to prevent the local extinction of this species.
\end{abstract}

Keywords Galliformes, generalized linear model, green pea fowl, mainland South-east Asia, species distribution models, Pavo muticus, stronghold population

\footnotetext{
Niti Sukumal (Corresponding author) and Tommaso Savini Conservation Ecology Program, School of Bioresources \& Technology, King Mongkut's University of Technology Thonburi, 49 Soi Thian Thale 25, Bang Khun Thian Chai Thale Road, Tha Kham, Bang Khun Thain, Bangkok 10150, Thailand E-mail niti_230@hotmail.com

Simon D. Dowell Chester Zoo, Upton-by-Chester, Chester, UK

Received 7 June 2018. Revision requested 8 August 2018.

Accepted 21 January 2019. First published online 23 October 2019.
}

Supplementary material for this article is available at https://doi.org/10.1017/So03060531900005X

\section{Introduction}

etermining the extent of suitable habitat to effectively plan species management is a challenge, especially for poorly studied areas. Lack of ecological and biological information for species of conservation concern is often a barrier to constructing reliable habitat selection models and predicting the availability of suitable habitat over wider areas.

Quantitative models are used widely to describe landscape patterns and predict species distribution, providing useful ecological insight, strong predictive capacity and potential for applied conservation (Elith \& Leathwick, 2009; Pearson, 2010). Models are built on the relationship between species presence records and environmental variables predicting the distribution of selected species (Elith \& Leathwick, 2009). Accurate distribution models require spatial predictor variables that are ecologically relevant for the modelled species (He et al., 2015). Predicted results can be used to guide field surveys towards regions where threatened species are likely to occur, and to identify sites where conservation and management actions should be prioritized (Pearson, 2010). Researchers often have to rely on species presence data alone, and several studies have used Maxent software (Philips et al., 2006) to produce species distribution maps from presence-only data. However, the effectiveness of Maxent software has been questioned as it produces a number of poorly defined indices. This can cause inferential error or under-estimation of population sizes compared to estimates produced with logistic regression models that facilitate more easily interpretable ecological quantities (Royle et al., 2012).

The green peafowl Pavo muticus would benefit from landscape-scale distribution modelling to aid its conservation. It was recategorized from Vulnerable to Endangered on the IUCN Red List in 2009 because of high hunting pressure and habitat destruction (BirdLife International, 2016). The historic species distribution covered almost the entire dry forest area of South-east Asia, including north-east India, Bangladesh, Yunnan (south-west China), Myanmar, Thailand, Lao, Viet Nam, northern Cambodia, Java 
(Indonesia) and peninsular Malaysia (McGowan et al., 1999). However, the populations in Bangladesh and Malaysia are considered extinct (BirdLife International, 2016) and the remaining population in Indochina is at risk from hunting (Brickle et al., 2008).

The objectives of this study were (1) to predict the extent of remaining suitable habitat for the green peafowl in mainland South-east Asia that could host viable populations, and to define how much of the species' range was lost over the past century, (2) to identify key localities with a sufficiently large patch of suitable habitat to contribute to the long-term survival of this species, (3) to prioritize locations where surveys to estimate population densities and monitor the longterm changes should be implemented as part of management plans and (4) to highlight locations outside protected areas where management and outreach programmes are required to maintain the green peafowl population.

\section{Study area}

We modelled green peafowl distribution for the remaining parts of the species' range in mainland South-east Asia (Myanmar, Thailand, Lao, Cambodia and Viet Nam). We excluded eastern India because there are no reliable records from this area. We also excluded China, which has been studied separately (Kong et al., 2018 provide evidence for a recent decline in the populations in Yunnan and Tibet), and Java as the geographical separation of the Javanese green peafowl populations led to differences in their ecology and response to human disturbance (Van Balen et al., 1995; McGowan et al., 1999).

\section{Methods}

\section{Species record locations}

We gathered locations of 901 individual records (visual, calls and camera-trap photos) from Boakes et al. (2010) and from the Global Biodiversity Information Facility (GBIF, 2016), which were collected during 1874-2015. We divided record locations into two data sets: total records (1874-2015, 901 records) and recent records (2009-2015, 487 records), which define the confirmed changes from declining to stable remaining populations (Boakes et al., 2010; GBIF, 2016). Total records were used to model the green peafowl's historical occurrence range. We used land-cover data from 2009 to input habitat variables for modelling the probability of occurrence.

We created a $1-\mathrm{km}$ radius circular plot around each record. When two circular plots overlapped $>5 \%$ we selected only the location of the latest record to represent the area. The radius of $1 \mathrm{~km}$ was selected based on the farthest detection distance for both auditory and visual detection of the green pea fowl (Indrawan, 1995; Brickle et al., 1998; Sukumal et al., 2015). We derived 337 circular plots from total records and 125 from recent records for habitat assessment to model the historical and recent occurrence range, respectively.

\section{Habitat variables data}

We used a total of 14 habitat variables for modelling probability of occurrence. Altitude data were obtained from WorldClim (2005), and land-cover variables were derived from GlobCover LandCover 2009 (Bontemps et al., 2011). We recategorized land-cover data to ensure they were compatible with mainland South-east Asian land-cover types. Starting with 22 original land-cover types, we grouped our data into 13 land-cover categories. We compared the resulting categories with geographical information system (GIS) databases from each country to check for accuracy (Supplementary Table 1).

\section{Probability of occurrence modelling}

We used the total records to model the historical probability of occurrence and the recent records to model the current probability of occurrence. We constructed probability of occurrence models using an infinite weight logistic model (Hefley \& Hooten, 2015) to investigate the relationship between given habitat covariates and probability of occurrence from a used vs available habitat selection model. Used locations were based on presence-only data from each dataset. Available locations were generated from systematic random sampling by placing locations at $5-\mathrm{km}$ intervals within the rectangular extent covering used locations. We determined the rectangular extent of used and available locations using clip and sampling tool extensions in ArcGIS 10.3.1 (Esri, Redlands, USA; Supplementary Fig. 1). We created a 1-km circular plot around each available location and determined altitude and land-cover type (based on the 13 land-cover categories) for each plot. We standardized continuous variables to transform the data to the same scale. This was achieved by subtracting the mean from the value and dividing by the standard deviation (Gelman, 2008). We used the Monte Carlo method to determine the adequate number of available locations used in the model based on the stabilized $\beta$ coefficient of the best-fit model. In total we used 15,965 available locations to compare with recent records and 207,827 to compare with total records. We conducted all statistical analyses in $R$ 3.3.1 (R Development Core Team, 2014).

We selected the best-performing model by the lowest Akaike information criterion (AIC). This model provides the best estimate of coefficient values for each habitat variable. We then created a grid of $3.14 \mathrm{~km}^{2}$-squares (to be 
standardized with 1 -km radius circular plots) covering mainland South-east Asia and generated a map of the predicted probability of occurrence for the green peafowl in each grid cell. To define the probability of occurrence model for the historical range (total records, 337 records), we used the 2009 GIS database for habitat variables, assuming that the original suitable habitat was still present before 2009 and that any local extinction before 2009 was not caused by habitat loss (McGowan et al., 1999; Madge \& McGowan, 2002; see Fig. 1 for a summary and Supplementary Table 1 for details).

We included a total of 15,965 available random locations to compare with recent record locations, and 207,827 available random locations to compare with total record locations.

\section{Identifying key localities}

We identified key localities based on overlap between the high probability of occurrence map $(p>0.5)$, the open forest map, and recent records. The open forest map combined deciduous, mixed evergreen and deciduous forest, and forest mixed with grassland from the GIS database. We grouped key localities into three categories: (1) high potential and confirmed areas, with overlap between high probability of occurrence areas, open forest, and recent record locations, (2) potential and confirmed areas, with overlap between open forest and recent record locations and (3) high potential but not confirmed areas, with overlap between high probability of occurrence areas, open forest, and historical records (Fig. 3).

To examine the protection level of key locality areas, we overlaid the protected area boundaries over potential areas of occurrence. To investigate habitat outside protected areas, we overlaid forest and agriculture cover over potential areas of occurrence in grid cells outside protected areas. The area with a high probability of occurrence $(p>0.5)$ based on recent records (Fig. $2 b$ ) was overlaid with protected areas (UNEP-WCMC \& IUCN, 2014), open forest areas (deciduous forest, mixed evergreen and deciduous forest), and agricultural areas (Ramankutty et al., 2010) to investigate the situation in each country in more detail.

\section{Predicting population number and stronghold areas}

We used the estimated density of 0.253 calling birds $/ \mathrm{km}^{2}$ for the highly disturbed YokDon National Park, Viet Nam, (Sukumal et al., 2015) as the minimum population density. We multiplied this value by the size of key localities to obtain an estimate of the minimum population size. The maximum estimated density was 11.343 calling birds $/ \mathrm{km}^{2}$ in HuaiKhaKhaeng Wildlife Sanctuary, Thailand, an area with very little disturbance (Sukumal et al., 2017). With this, we calculated the maximum population size estimate for each key locality. We assumed 500 individuals to be the minimum required for long-term survival of a population, based on studies of other Galliformes (Grimm \& Storch, 2000; Zhang \& Zheng, 2007). We used this value to determine areas holding a viable population (minimum $44 \mathrm{~km}^{2}$ of suitable area based on the maximum density estimation).

Based on this we defined stronghold areas as those with an estimated population $>500$ individuals, with high population density and low intensity of disturbance, the latter being defined as overlapping with protected areas.

\section{Results}

\section{Probability of occurrence and key localities}

The best model (lowest AIC) included altitude and forest mixed with grassland. Using total records, the range model showed the probability of occurrence being significantly negatively influenced by altitude and cropland, but positively influenced by area of forest mixed with grassland (Table 1, Fig. 2a). Using recent records the probability of occurrence was negatively influenced by altitude but positively by forest mixed with grassland (Table 1, Fig. 2b).

In Myanmar the remaining suitable habitat for the green peafowl is predicted to be $88,118 \mathrm{~km}^{2}$ ( $19 \%$ of the historical range), divided into four locations (protected areas in key localities 1 and 2; Table 2, Fig. 3) In Thailand the model predicted remaining suitable habitat to be $33,105 \mathrm{~km}^{2}$ (18.5\% of the historical range). The highest population density of 11.343 calling birds $/ \mathrm{km}^{2}$ is in the highly protected HuaiKhaKhaeng Wildlife Sanctuary (Table 2, Fig. 3). A second important population was found in neighbouring protected areas at key locality 5 (N. Sukumal, pers. obs.; Table 2, Fig. 3). There is an area of contiguous locations with confirmed recent records in protected areas at key locality 4 (Table 2, Fig. 3).

Remaining suitable habitat in Lao is predicted to be $30,439 \mathrm{~km}^{2}$ (14.9\% of the historical range). Green peafowl was only reported in 2002 from one site in the south, close to the Cambodian and Thai border, in Dong Khanthung Provincial Protected Area (Vongkhamheng et al., 2012; Table 2).

For Cambodia our model predicted remaining suitable habitat to be $14,256 \mathrm{~km}^{2}$ (13.2\% of the historical range), mostly in the north and east of the country. Recent records from 2008-2010 are available for key localities 10 and 11. In the eastern dry plains the species was recorded during 20052014 in protected areas at key localities 12 and 14 (Table 2). Outside these protected areas our model predicted that a 


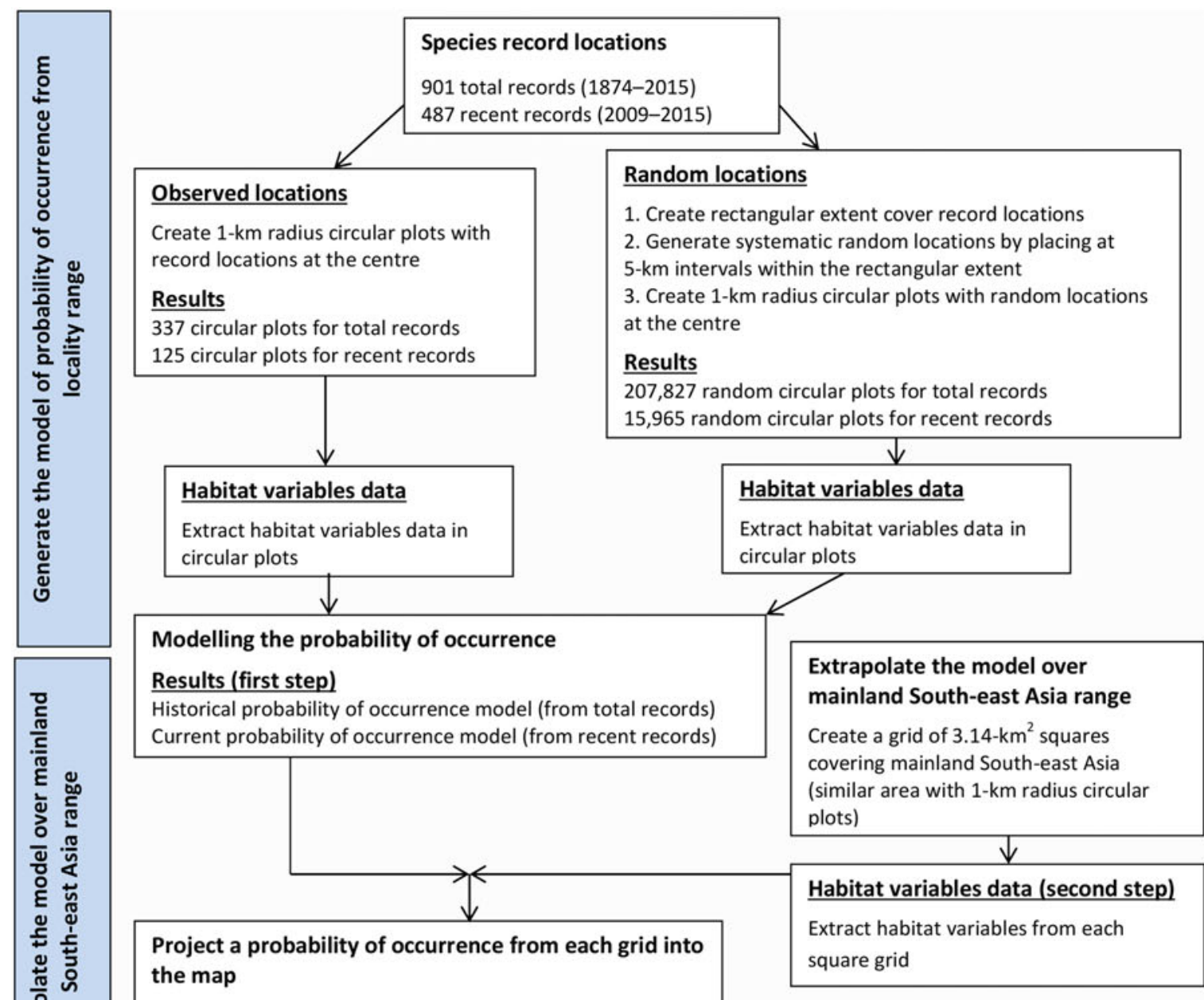

Results (third step)

Historical probability of occurrence map (FIG. 2a)

Current probability of occurrence map (FIG. 2b)

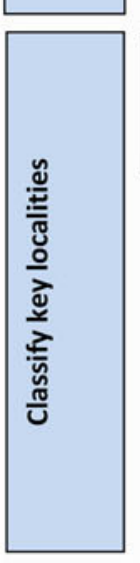

$\downarrow$

Produce a map of current probability of occurrence (FIG. 2b), select only P > 0.5 (high probability of occurrence)

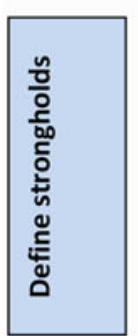

\section{Predicting population number}

Multiply minimum density $\left(0.253\right.$ calling birds $\left./ \mathrm{km}^{2}\right)$ and maximum density ( 11.343 calling birds $/ \mathrm{km}^{2}$ ) with the size of key localities to estimate population size

Results (FIG. 5)

1) Estimated population $>500$ individuals (for maximum estimated population)

2) Overlap with protected areas

FIG. 1 Flow chart depicting the sequence of analytical steps used to define stronghold areas (see Methods for details). 

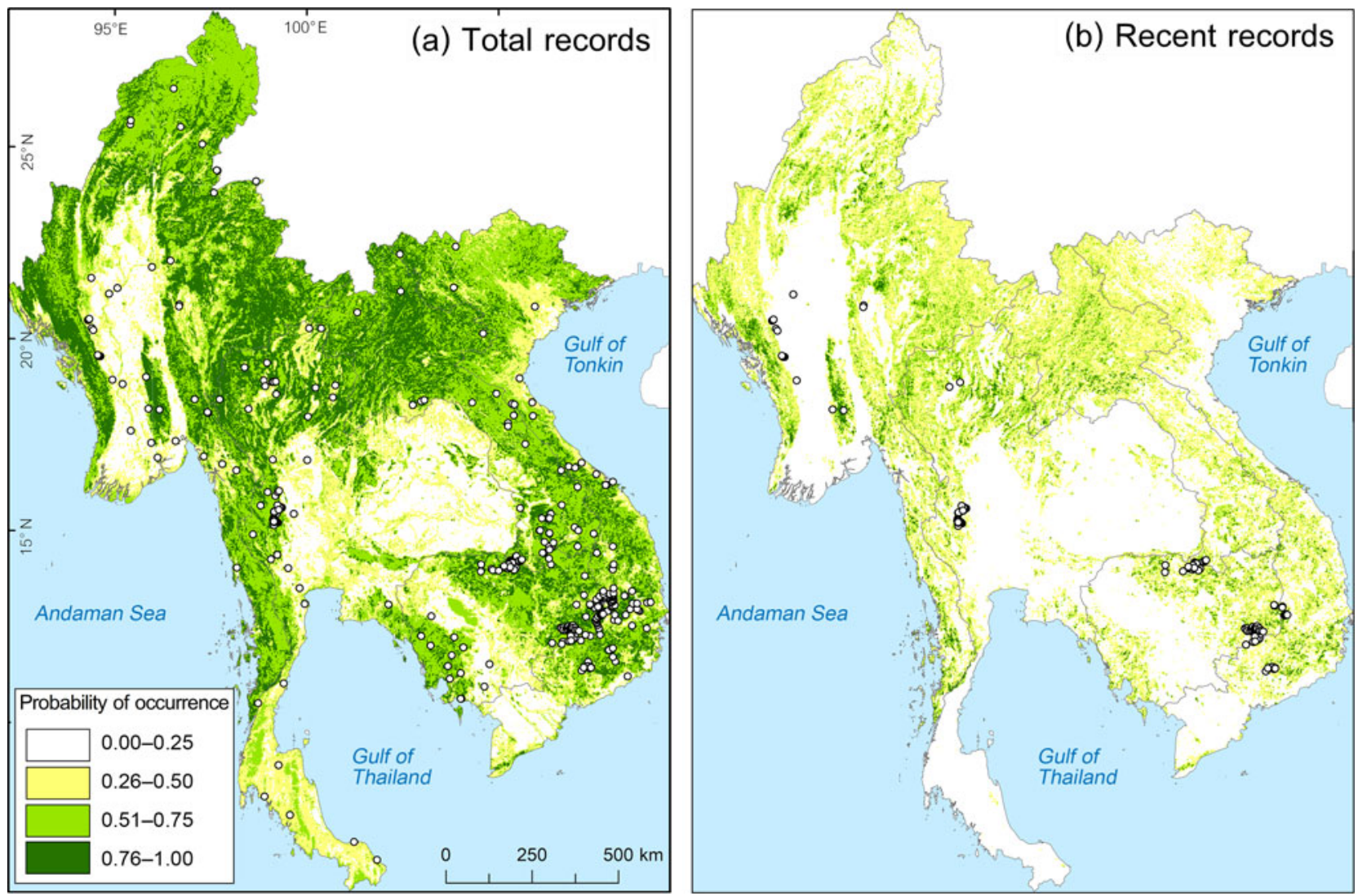

Fig. 2 Predicted green peafowl Pavo muticus distribution from modelling based on (a) total records (1874-2015) and (b) recent records (2009-2015).

further $550.38 \mathrm{~km}^{2}$ had a high probability of occurrence (Fig. 4a,b).

Remaining habitat suitable for green peafowl is predicted to be $19,681 \mathrm{~km}^{2}$ in Viet Nam (9.4\% of the historical range). The area with the highest potential is YokDon National Park, connected to five protected areas in the dry eastern plains of Cambodia (Fig. 3). However, this site shows high levels of disturbance (Sukumal et al., 2015). Another location is CatTien National Park, which contains scattered habitat patches (Table 2, Fig. 3).

\section{Defining stronghold locations}

Our model predicted two potential and four confirmed stronghold populations (Fig. 5).

The two potential strongholds were labelled (a) and (b). Stronghold (a) is represented by the complex of three protected areas (key locality 2, Table 2). Stronghold (b) in north-west Thailand and adjacent south-east Myanmar is a large continuous patch of potential habitat covered by six protected areas on the Thai side and unprotected areas in Myanmar (key locality 3, Table 2).

We applied the labels (c), (d), (e) and (f) to the confirmed strongholds. Stronghold (c) in north Thailand comprised nine protected areas with a high protection level in key localities 4 and 5 (Table 2). Stronghold (d) in HuaiKhaKaeng Wildlife Sanctuary is a highly protected area that showed a population increase (key locality 6, Table 2) over the last decade (Sukumal et al., 2017). Stronghold (e) is located outside protected areas in southern Lao and connected to PreahVihear Protected Forest and Kuloen Promtep Protected Forest in Cambodia. If the different key locations of this stronghold can be connected and protection improved the area is expected to host a viable population (Table 2). Stronghold (f) is a large patch located within four contiguous protected areas in eastern Cambodia and one in Viet Nam (key localities 12 and 14, Table 2).

\section{Discussion}

Our model predicted that a total of $185,602 \mathrm{~km}^{2}$ of habitat suitable for the green peafowl remains across its range in mainland South-east Asia. This represents a decrease of $84 \%$ compared to the historical distribution. Thus the species occurs in only $16 \%$ of its estimated original range covering the recently defined South-east Asia savannah woodland (Ratnam et al., 2016). The key localities with capacity to contribute to the long-term survival of this species are mostly limited to protected areas $(28$ protected areas in total; Table 2). However, the protection level varies between 


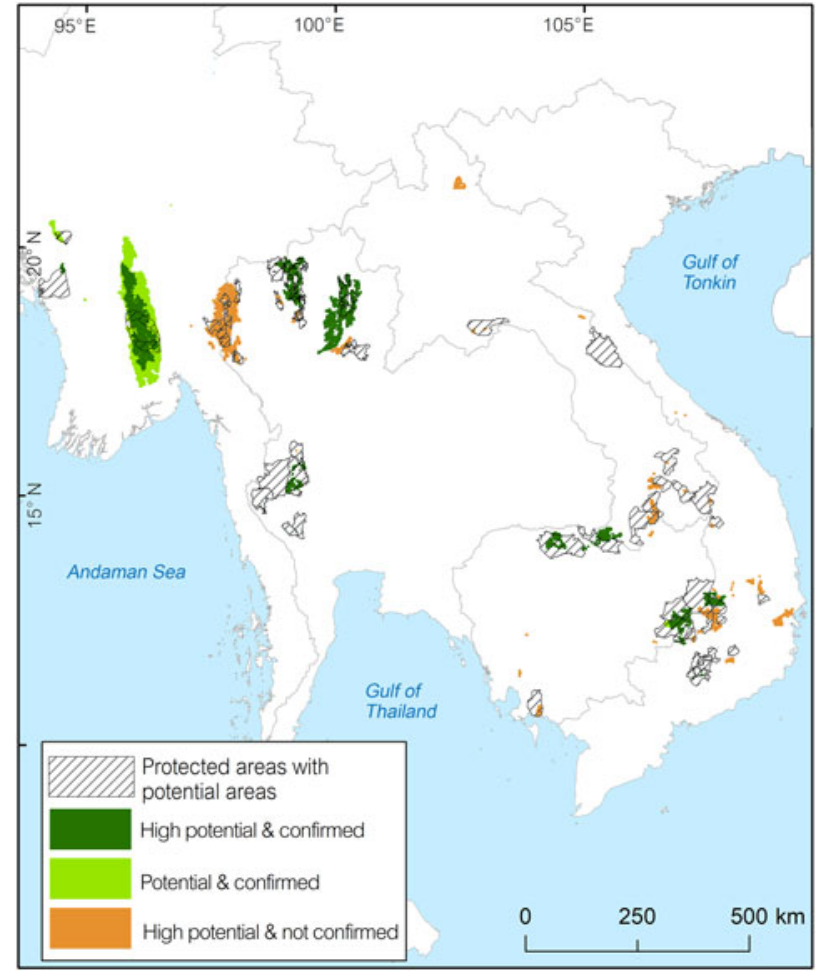

FIG. 3 Potential areas classified as (1) high potential and confirmed areas from overlay between contiguous areas of high probability of occurrence $(\mathrm{P}>0.5)$ based on recent record model, open forest (dry dipterocarp forest, mixed deciduous forest, and forest mixed with grassland), and recent record locations; (2) potential and confirmed areas from overlay between open forest and recent record locations; and (3) high potential but unconfirmed areas from overlay between high probability of occurrence $(\mathrm{P}>0.5)$ based on recent record model, open forest, and historical record locations. Hatched polygons are protected areas that overlap with potential areas.

different areas, with many requiring mitigation of disturbance and hunting. We predict six population strongholds, which are mostly inside protected areas. Only one stronghold in southern Myanmar is outside protected areas and overlaps with agricultural areas.

\section{Population strongholds in protected areas}

Most lowland habitat inside protected areas within the green peafowl's range is experiencing high levels of human disturbance, mainly through hunting/poaching and agricultural encroachment (Brickle et al., 2008, Kong et al., 2018). However, the green peafowl shows tolerance to habitat degradation and can recover following protection, as has been shown in western Thailand (Sukumal et al., 2017) and south Viet Nam (Sukumal et al., 2015).

With effective protection and management that lowers poaching pressure inside and outside the protected areas, the large potential stronghold (a) in Myanmar (Fig. 5)
TABLE 1 Parameters that influence the probability of occurrence model based on recent and total records of the green peafowl Pavo muticus.

\begin{tabular}{lcrl}
\hline Parameters & \multicolumn{1}{c}{$z$-value } & P-value \\
\hline Modelling based on recent records (AIC $=\mathbf{3 , 6 9 8 . 3})$ & \\
(Intercept) & -13.890 & -116.675 & $<0.0001^{\star *}$ \\
Altitude & -0.0014 & -4.847 & $<0.0001^{\star *}$ \\
Forest mixed with grassland & 0.661 & 8.011 & $<0.0001^{\star *}$ \\
$\quad$ areas & & & \\
Modelling based on historical records (AIC = 11,083) \\
(Intercept) & -15.059 & -187.631 & $<0.0001$ \\
Altitude & -0.002 & -8.457 & $<0.0001^{\star *}$ \\
Forest mixed with grassland & 0.146 & 2.337 & $0.0190^{\star}$ \\
$\quad$ areas & & & \\
Cropland areas & -0.495 & -7.010 & $<0.0001^{\star *}$ \\
\hline
\end{tabular}

${ }^{\star} \mathrm{P}<0.05 ;{ }^{* *} \mathrm{P}<0.0001$.

could become one of the main areas contributing to the species' long-term persistence in the western part of its range. To enable conservation management and planning in this area, an extensive population monitoring programme is needed to estimate the species' distribution, density and threats to its survival.

In Thailand, stronghold (d) in HuaiKhaKhaeng Wildlife Sanctuary is the most important area for the species (Fig. 5). This sanctuary is included in the Western Forest Complex, considered the largest remaining forest tract in mainland South-east Asia (designated UNESCO World Heritage Site; WEFCOM, 2004). This population is highly protected with frequent patrols preventing disturbance (i.e. poaching), a consequence of the large resident tiger population in the area (Duangchantrasiri et al., 2015), and showed a clear improvement since 1992 (Sukumal et al., 2017). There is potential for the resident population to expand to adjacent protected areas such as ThungYai Naresuan Wildlife Sanctuary.

Stronghold (c) in northern Thailand is located in contiguous protected areas (Fig. 5). The species' presence in the area was confirmed, but the threat level is still unclear and a monitoring programme is required to investigate population size and threats. In the north-western part of Thailand the potential stronghold (b), including six small protected areas (Fig. 5), could be an important site for the green peafowl, but surveys are required to confirm the presence of the species before estimating its population density.

In Cambodia and Viet Nam we identified two potential strongholds within protected areas. The largest stronghold (f) in the eastern dry plains of Cambodia is expected to host the main population in the country (Gray et al., 2014; key localities 12 and 14 of stronghold (f) in Fig. 5). This area is connected with YokDon National Park in south-central Viet Nam, which used to host one of the main populations in that country (Brickle, 2002), although this has declined 
TABLE 2 Predicted number of calling green peafowl males across sites in mainland South-east Asia. The minimum number of calling males is based on a density of $0.253 / \mathrm{km}^{2}$ observed in YokDon National Park, Viet Nam, an area with a high level of anthropogenic disturbance (Sukumal et al., 2015). The maximum number is based on $11.343 / \mathrm{km}^{2}$, as observed in HuaiKhaKhaeng Wildlife Sanctuary, Thailand, where anthropogenic disturbance is low (Sukumal et al., 2017).

\begin{tabular}{|c|c|c|c|c|c|c|c|}
\hline \multirow{2}{*}{$\begin{array}{l}\text { Key } \\
\text { locality }\end{array}$} & \multirow[b]{2}{*}{ Name of overlapping protected areas ${ }^{1}$} & \multirow[b]{2}{*}{ Country } & \multirow{2}{*}{$\begin{array}{l}\text { Area } \\
\left(\mathrm{km}^{2}\right)\end{array}$} & \multirow{2}{*}{$\begin{array}{l}\text { Range of highest } \\
\text { probability of } \\
\text { occurrence }\end{array}$} & \multicolumn{2}{|c|}{ No. of calling males } & \multirow{2}{*}{$\begin{array}{l}\% \text { of stronghold } \\
\text { areas within } \\
\text { protected areas }\end{array}$} \\
\hline & & & & & Minimum & Maximum & \\
\hline 1 & Shwesettaw WS & Myanmar & 203.69 & $0-0.25$ & 52 & 2,310 & 35.20 \\
\hline 2 & $\begin{array}{l}\text { Pegu Yomas NP, Bago Yoma NP, } \\
\text { Shinpinkyetthauk WS }\end{array}$ & Myanmar & $13,413.77$ & $>0.75$ & 3,394 & 152,152 & 32.38 \\
\hline 3 & $\begin{array}{l}\text { Mae Ngao NP, Namtok Mae Surin } \\
\text { NP, Salawin NP, Doi Wiang La WS, } \\
\text { Mae Yom Phang Khwa WS, Salawin } \\
\text { WS }\end{array}$ & Thailand & $3,984.85$ & $>0.75$ & 1,008 & 45,200 & 37.79 \\
\hline 4 & $\begin{array}{l}\text { Chiang Dao WS, Mae Ta Khai NP, } \\
\text { Doi Wiang Pha NP, Sri Lanna NP }\end{array}$ & Thailand & $1,624.56$ & $>0.75$ & 411 & 18,427 & 84.78 \\
\hline 5 & $\begin{array}{l}\text { WiangLo WS, DoiPhuNang NP, } \\
\text { TubPhaYaLo Non-Hunting Area, } \\
\text { MaeYom NP, Lam Nam Nan NP }\end{array}$ & Thailand & $3,615.52$ & $>0.75$ & 915 & 41,011 & 25.73 \\
\hline 6 & Huai Kha Khaeng WS & Thailand & 377.21 & $>0.75$ & 95 & 4,279 & 93.74 \\
\hline 7 & Phongsaly Province & Lao & 193.79 & $>0.75$ & 49 & 2,198 & \\
\hline 8 & $\begin{array}{l}\text { Phou Kateup NP (Bolovens } \\
\text { Northeast) }\end{array}$ & Lao & 213.39 & $>0.75$ & 54 & 2,420 & \\
\hline 9 & Xe Khampho NP, Xe Pian NP & Lao & 289.65 & $>0.75$ & 73 & 3,285 & \\
\hline 10 & Preah Vihear PF & Cambodia & 530.69 & $>0.75$ & 134 & 6,020 & 8.66 \\
\hline 11 & Kulen Promtep WS & & 468.32 & $>0.75$ & 118 & 5,312 & 93.02 \\
\hline 12 & Mondulkiri PF, Yok Don NP & $\begin{array}{l}\text { Cambodia \& } \\
\text { Viet Nam }\end{array}$ & 597.63 & $>0.75$ & 151 & 6,779 & 96.74 \\
\hline 13 & Dak Mang NR & Viet Nam & 595.09 & $>0.75$ & 151 & 6,750 & 3.54 \\
\hline 14 & $\begin{array}{l}\text { Seima PF, Snoul WS, Phnom Prich } \\
\text { WS }\end{array}$ & Cambodia & 857.52 & $>0.75$ & 217 & 9,727 & 99.77 \\
\hline 15 & Preah Monivong (Bokor) NP & Cambodia & 96.89 & $>0.75$ & 25 & 1,099 & \\
\hline 16 & Ea So NR & Viet Nam & 195.65 & $0.51-0.75$ & 50 & 2,219 & \\
\hline 17 & Lam Dong Province & Viet Nam & 90.10 & $>0.75$ & 23 & 1,022 & \\
\hline 18 & Khanh Hoa Province & Viet Nam & 362.12 & $>0.75$ & 92 & 4,107 & \\
\hline
\end{tabular}

${ }^{1}$ NP, National Park; NR, Nature Reserve; PF, Protected Forest; WS, Wildlife Sanctuary.

${ }^{2}$ Blank cells indicate that the key locality was outside a stronghold.

sharply in recent years (Sukumal et al., 2015). This stronghold has been intensively surveyed by the World Wide Fund for Nature and the Wildlife Conservation Society Cambodia (Gray et al., 2014), resulting in a green peafowl density higher than that estimated in neighbouring YokDon National Park (Chandara, 2017), where high hunting pressure and habitat disturbance have caused a large decline over the past decade (Sukumal et al., 2015). The higher recorded density on the Cambodian side of the border could aid recovery of the population on the Vietnamese side if protection could be enhanced and hunting reduced. Overall the entire stronghold requires better protection; decreases in other wildlife populations have been reported as a result of high hunting pressure (Rostro-Garcia et al., 2016).

The second stronghold in Cambodia is stronghold (e) in the northern part of the country (Fig. 5) where discrete habitat patches are contiguous with unprotected ones in southern Lao. In this stronghold the green peafowl was reported to be widespread but at low density (Goes, 2009). A systematic survey is required to confirm distribution and density, and to investigate the variables that may affect the population. It is also necessary to manage patch connectivity between these two protected areas.

\section{Population stronghold outside protected areas}

In Myanmar a large potential stronghold outside protected areas is stronghold (a) in the central part of the country (Fig. 5), mostly overlapping with agricultural areas (63.15\% overlap). The species' presence was confirmed by a research project conducted during April-May 2013 in part of North Zamayi Reserve Forest (Fig. 3). In addition, our investigations during January 2018 found a footprint and feather of this species and captive birds trapped by villagers at six sites in this area. 

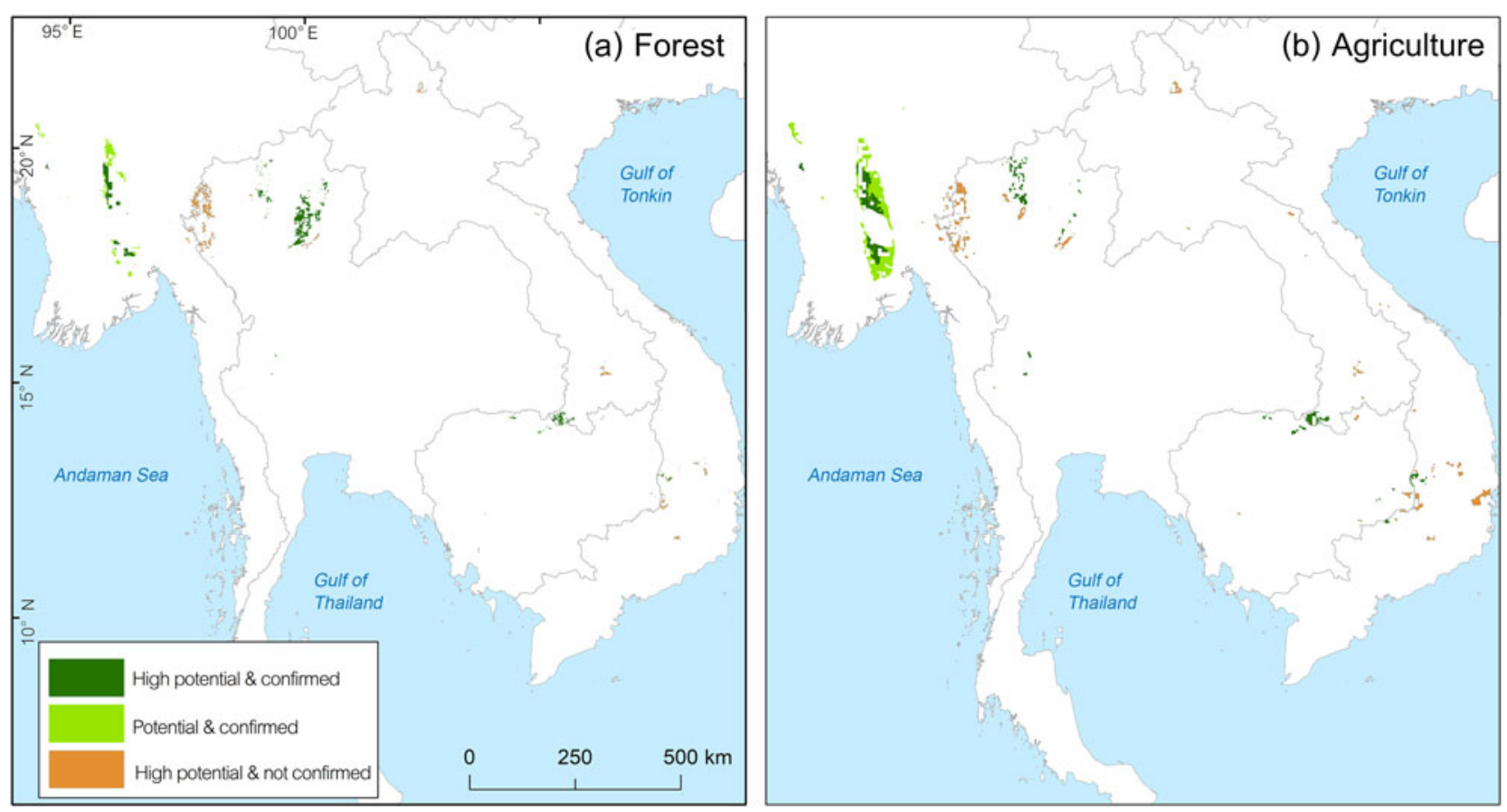

FIG. 4 Potential areas outside protected areas which are (a) inside unprotected open forest and (b) overlapping with agricultural areas.

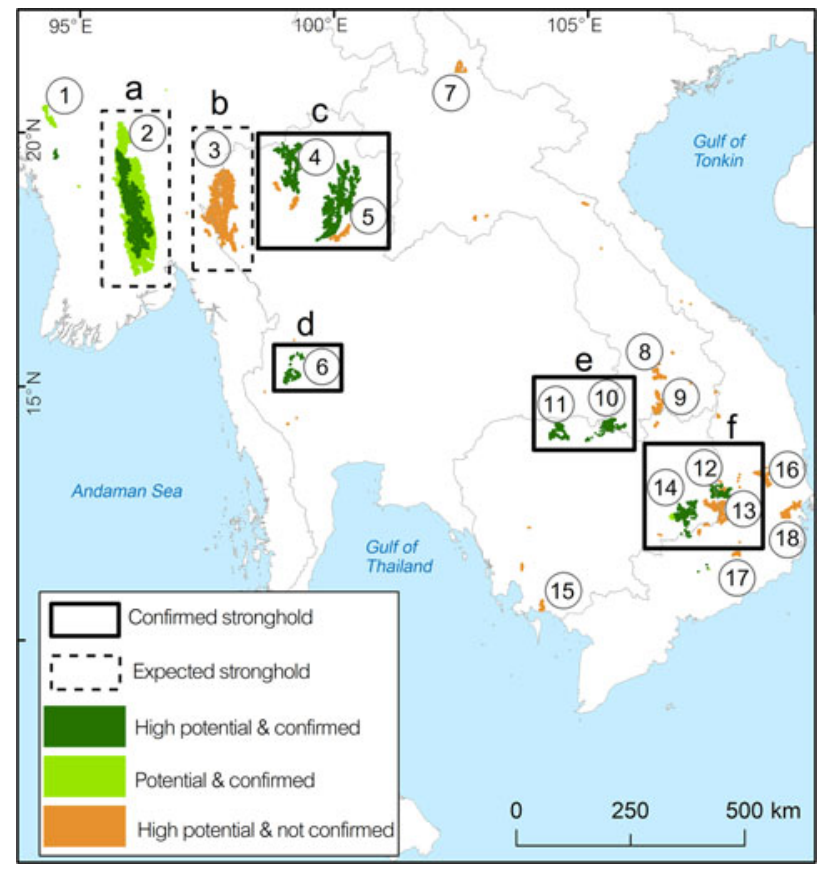

FIG. 5 Predicted stronghold areas for green peafowl populations. Solid rectangles are confirmed stronghold areas, defined as having medium to high levels of protection and contiguous areas of protected land. Dashed rectangles are expected stronghold areas, defined by large patches of suitable habitat but requiring confirmation of species records and density estimation. Numbers in circles refer to key localities (Table 2).

So far this potential stronghold has not received much conservation attention, and a high poaching rate was recently reported despite conservation actions carried out to support resident Asian elephant Elephas maximus populations (Sampson et al., 2018). The development of an education outreach programme aimed at increasing the local community's awareness of wildlife protection would benefit the green peafowl. Local conservation groups could be set up to address and mitigate disturbance and poaching, with the aim to secure the long-term survival of this and other wildlife species. This has proved a successful strategy in a different area in Shan state, Myanmar, where a local community environmental protection group has taken steps to protect a small peafowl population (Mu Aung et al., 2018).

In Thailand the potential stronghold (b), not yet included in the protected area system, is in the north-western part of the country close to the Myanmar border (Fig. 5). The habitat in this stronghold is scattered between small protected areas and unprotected forest. A survey is required to confirm the presence of a green peafowl population and its status. Stronghold (c) is a second stronghold with scattered habitat patches connecting protected areas (Fig. 5). These areas require management with a particular focus on patch connectivity between protected areas. A conservation outreach programme may also be required to mitigate hunting pressure. Conservation actions in this area are currently focused on adapting specific agricultural patches, primarily at the edge of protected areas, to provide open lekking areas during the breeding season. Such activities, including leaving parts of fields unplanted and cutting shrubs, were recently carried out by villagers living adjacent to protected areas (N. Sukumal, pers. obs.).

In southern Lao the DongKhanthung Provincial Protected Area, included in the potential key locality 10 (Fig. 5), 
was reported to have a viable green peafowl population but is facing high hunting pressure and habitat degradation (Vongkhamheng et al., 2012). Establishment of an education outreach programme and the setting up of a local conservation group in this area may help reduce habitat disturbance and hunting pressure.

In eastern Cambodia several patches scattered between protected areas (key locality 13, Fig. 5) could create connections between the four major protected areas in Cambodia and two in Viet Nam. Achieving patch connectivity and decreasing hunting pressure are priorities. An education outreach programme may be required around these protected areas to increase awareness amongst the local community.

\section{Other potential areas}

Small patches of potentially suitable habitat are scattered across the species' range, with confirmed species records from western Myanmar (key locality 1, Fig. 5). These areas are located both inside and outside protected areas adjacent to large patches of suitable unprotected forest (Fig. 2b). A systematic survey to estimate population density is needed. We also recommend the establishment of a protected area to connect with Shwesettaw Wildlife Sanctuary. Our model identified other small key localities across mainland South-east Asia but the species' presence is not confirmed. We therefore suggest detailed surveys in these areas (key localities 5, 7, 8, 9, 15, 16, 17 and 18; Fig. 5), which are located inside and outside protected areas (Table 2).

\section{Conservation implications}

The most suitable habitat for the green peafowl is concentrated in lowland open dry forest (Fig. 2b, Table 1). This habitat is now decreasing and becoming fragmented as a result of agriculture and construction encroachment. Because of the economic importance of these localities, most protected areas have been designated at higher altitudes (Round, 2014). Programmes aimed at improving local community awareness and exploring alternative livelihoods are necessary to mitigate the anthropogenic threats to the remaining lowland habitats and ensure the long-term conservation of the green peafowl and other lowland forest species.

The recent range and distribution of the green peafowl have rapidly contracted compared to the assumed historical distribution. Most of the remaining populations are now restricted to protected areas of varying protection levels, with some areas showing advanced deterioration of the population (Harrison et al., 2016).

Only one area, HuaiKhaKhaeng Wildlife Sanctuary in Thailand, was confirmed to have a well-protected, viable population at a healthy population density (Sukumal et al.,
2017). Other strongholds with large patches of suitable habitat (Fig. 5) still require density estimates and research on the variables affecting long-term survival of the green peafowl. Increasing protection activities (i.e. patrolling) improved both green peafowl and other wildlife populations inside protected areas (Duangchantrasiri et al., 2015; Sukumal et al., 2017), but increased awareness amongst local communities around these areas is also necessary to support long-term conservation. In addition, increasing green peafowl populations could help support the recovery of large predators that prey on them (Sukumal et al., 2017). This could affect, for example, the rapidly declining South-east Asian leopard Panthera pardus delacouri, which only remains in a few areas that largely overlap with green peafowl habitat in key localities 2, 3, 6, 12, 13 and 14 (Fig. 5; Rostro-Garcia et al., 2016). Other associated species with overlapping distribution include the tiger Panthera tigris and banteng Bos javanicus. We recommend further investigation of the range overlap of these species and their co-dependencies.

Acknowledgements This research was supported by King Mongkut's University of Technology Thonburi, Thailand (grant numbers KM-Wor1 56_peafowl and 3-TMB-peafowl-KM55) and the Rufford Small Grant Foundation (grant number 17837-2). NS was supported by the Royal Golden Jubilee Ph.D. Program, Thailand (grant number PHD/0105/2553) and the Newton Fund. We thank M. Grainger, J.C. Dunn, T.N.E. Gray, M. Nuttall, and A. Mould for supplying data on green peafowl record locations; N. Tantipisanuh and D. Ngoprasert for help with data analysis; Khin Maung Oo, N.M. Shwe, WWF Cambodia for assistance with fieldwork; P.D. Round, S.J. Brown and G.A. Gale for their critiques.

Author contributions Project design: NS, SDD, TS; data analysis and writing: all authors.

\section{Conflicts of interest None.}

Ethical standards This research abided by the Oryx guidelines on ethical standards and did not involve human subjects, experimentation with animals or collection of specimens.

\section{References}

Birdife International (2016) Pavo muticus. In The IUCN Red List of Threatened Species 2016: e.T22679440A92814720. Http://dx.doi. org/10.2305/IUCN.UK.2016-3.RLTS.T22679440A92814720.en [accessed 1 March 2017].

Boakes, E., McGowan, P.J.K., Fuller, R.A., Chang-Qing, D., Clark, N.E., O’Connor, K. \& Mace, G.M. (2010) Distorted views of biodiversity: spatial and temporal bias in species occurrence data. PLOS Biology, 8, e1000385.

Bontemps, S., Defourny, P., van Bogaert, E., Ariono, O., Kalogirou, V. \& Perez, J.R. (2011) GlobCover 2009, Products Description and Validation Report. European Space Agency, Frascati, Italy, and Universite' Catholique de Louvain, Louvain-la-Neuve, Belgium. Http://due.esrin.esa.int/files/ GLOBCOVER2009_Validation_Report_2.2.pdf [accessed 29 December 2015]. 
BRICKLE, N.W. (2002) Habitat use, predicted distribution and conservation of green peafowl (Pavo muticus) in DakLak Province, Vietnam. Biological Conservation, 105, 189-197.

Brickle, N.W., Cu, N., QuyQuynh, H., TuCuong, N.T. \& Van SAN, H. (1998) The Status and Distribution of Green Peafowl in DakLak Province, Vietnam. BirdLife International-Vietnam Programme, Hanoi, Viet Nam.

Brickle, N.W., Duckworth, J.W., Tordoff, A.W., Pole, C.M., Timmins, R. \& McGowan, P.J.K. (2008) The status and conservation of Galliformes in Cambodia, Laos and Vietnam. Biodiversity and Conservation, 17, 1393-1427.

Chandara, T. (2017) Density estimation of gree peafowl Pavo muticus in Srepok Wildlife Sanctuary, Cambodia. MSc thesis, Royal University of Phnom Penh, Phnom Penh, Cambodia.

Duangchantrasiri, S.D., Umponjan, M., Simcharoen, S., Pattanavibool, A., Chaiwattana, S., Maneerat, S. et al. (2015) Dynamics of a low-density tiger population in Southeast Asia in the context of improved law enforcement. Conservation Biology, 30, 639-648.

Elith, J. \& Leathwick, R. (2009) Species distribution models: ecological explanation and prediction across space and time. Annual Review of Ecology, Evolution, and Systematics, 40, 677-697.

Gelman, A. (2008) Scaling regression inputs by dividing by two standard deviations. Statistics in Medicine, 27, 2865-2873.

Goes, F. (2009) The status and distribution of green peafowl Pavo muticus in Cambodia. Cambodia Journal of Natural History, 1, 7-15.

GBIF (The Global Biodiversity Information Facility) (2016) Global Biodiversity Information Facility. Free and Open Access to Biodiversity Data. GBIF Secretariat, Copenhagen, Denmark. Https://www.gbif.org [accessed 31 March 2016].

Gray, T.N.E., Pollard, E.H.B., Evans, T.D., Goes, F., Grindley, M., Omaliss, K. et al. (2014) Birds of Mondulkiri, Cambodia: distribution, status and conservation. Forktail, 30, 66-78.

Grimm, V. \& Storch, I. (2000) Minimum viable population size of capercaillie Tetrao urogallus: results from a stochastic model. Wildlife Biology, 6, 219-225.

Harrison, R.D., Sreekar, R., Brodie, J.F., Brook, S., Luskin, M., O'Kelly, H. et al. (2016) Impacts of hunting on tropical forests in Southeast Asia. Conservation Biology, 30, 972-981.

He, K.S., Bradley, B.A., Cord, A.F., Rocchini, D., Tuanmu, M., Schmidtlein, S. et al. (2015) Will remote sensing shape the next generation of species distribution models? Remote Sensing in Ecology and Conservation, 1, 4-18.

Hefley, T.J., \& Hooten, M.B. (2015) On the existence of maximum likelihood estimates for presence-only data. Methods in Ecology and Evolution, 6, 648-655.

InDRAWAN, M. (1995) Behaviour and abundance of green peafowl in Baluran National Park, east Jawa. MSc thesis, University of Aberdeen, Aberdeen, UK.

Kong, D., Wu, F., Shan, P., Gao, J., Yan, D., Luo, W. \& Yang, X. (2018) Status and distribution changes of the Endangered green peafowl (Pavo muticus) in China over the past three decades (1990s-2017). Avian Research, 9, 18.

Madge, S. \& McGowan, P.J.K. (2002) Pheasants, Partridges and Grouse. Christopher Helm, London, UK.

McGowan, P.J.K., Duckworth, J.W., Xianj, W., Van Balen, B., XiaOjun, Y., Khan, M.K.M. et al. (1999) A review of the status of the green peafowl Pavo muticus and recommendations for future action. Bird Conservation International, 9, 331-348.

Mu Aung, M., Win New, W. \& Naing Oo, T. (2018) Report on Assessment of Plant Species Diversity and Wildlife in Pindaya Township, Shan State, Myanmar. Forest Department, Yangon, Myanmar. Https://www.forestdepartment.gov.mm [accessed 30 October 2018].
Pearson, R.G. (2010) Species' Distribution Modeling for Conservation Educators and Practitioners, Lessons in Conservation. American Museum of Natural History, Centre for Biodiversity and Conservation, Network for Conservation Educators and Practitioners, USA. Http://ncep.amnh.org [accessed 6 September 2019].

Philips, S.J., Anderson, R.P. \& Schapire, R.E. (2006) Maximum entropy modeling of species geographic distributions. Ecological Modelling, 190, 231-259.

Ramankutty, N., Evan, A.T., Monfreda, C. \& Foley, J.A. (2010) Global Agricultural Lands: Croplands, 200o. NASA Socioeconomic Data and Applications Center (SEDAC), Palisades, USA. Https://doi.org/10.7927/H4C8276G [accessed 28 July 2016].

Ratnam, J., Tomlinson, K.W., Rasquinha, D.N. \& Sankaran, M. (2016) Savannahs of Asia: antiquity, biogeography, and an uncertain future. Philosophical Transactions of the Royal Society B: Biological Sciences, 371, 201150305.

R Development Core Team (2014) $R$ : a Language and Environmental for Statistical Computing. R Foundation for Statistical Computing, Vienna, Austria.

Rostro-Garcia, S., Kamler, J.F., Ash, E., Clements, G.R., Gibson, L., Lynam, A.J. et al. (2016) Endangered leopards: range collapse of the Indochinese leopard (Panthera pardus delacouri) in Southeast Asia. Biological Conservation, 201, 293-300.

Round, P.D. (2014) Gurney's pittas in Thailand-from rediscovery to extinction in just 28 years. Natural History Bulletin of the Siam Society, 60, 3-8.

Royle, J.A., Chandler, R.B., Yackulic, C., \& Nichols, J.D. (2012) Likelihood analysis of species occurrence probability from presence-only data for modeling species distributions. Methods in Ecology and Evolution, 3, 545-554.

Sampson, C., McEvoy, J., Min Oo, Z., Myo Chit, A., Nyein Chan, A., Tonkyn, D. et al. (2018) New elephant crisis in Asia-early warning signs from Myanmar. PLOS ONE, 13, e0194113.

Sukumal, N., McGowan, P.J.K. \& SAvini, T. (2015) Change in status of green peafowl Pavo muticus (Family Phasianidae) in Southcentral Vietnam: a comparison over 15 years. Global Ecology and Conservation, 3, 11-19.

Sukumal, N., Dowell, S. \& Savini, T. (2017) Micro-habitat selection and population recovery of the Endangered green peafowl Pavo muticus in western Thailand: a model for conservation guidance. Bird Conservation International, 27, 414-430.

UNEP-WCMC \& IUCN (2014) Protected Planet. World Database on Protected Areas. UNEP-WCMC \& IUCN, Cambridge, UK. Https://www.protectedplanet.net [accessed 16 April 2015].

Van Balen, S., Prawiradilaga, D.M. \& Indrawan, M. (1995) The distribution and status of green peafowl in Java. Biological Conseravtion, 71, 289-297.

Vongkhamheng, C., Phiapalath, P., Vongkhamheng, C. \& Ounmany, S. (2012) Participatory Survey, Assessment and Conservation of Green Peafowl (Pavo muticus) in Dongkhanthung Provincial Protected Area of Champasak, the Far South-western Lao PDR. Lao Wildlife Conservation Association, Vientiane, Lao PDR.

WEFCOM (Western Forest Complex Ecosystem Management Project) (2004) GIS Database and its Applications for Ecosystem Management. Bangkok, Thailand: the Western Forest Complex Ecosystem Management Project. Department of National Parks, Wildlife, and Plant Conservation, Bangkok, Thailand.

World Clim (2005) Global Climate Data. Free Climate Data for Ecological Modeling and GIS. Https://www.worldclim.org [23 February 2016].

Zhang, Y.Y. \& ZhenG, G.M. (2007) A population viability analysis (PVA) for Cabot's tragopan (Tragopan caboti) in Wuyanling, south-east China. Bird Conservation International, $17,151-161$. 